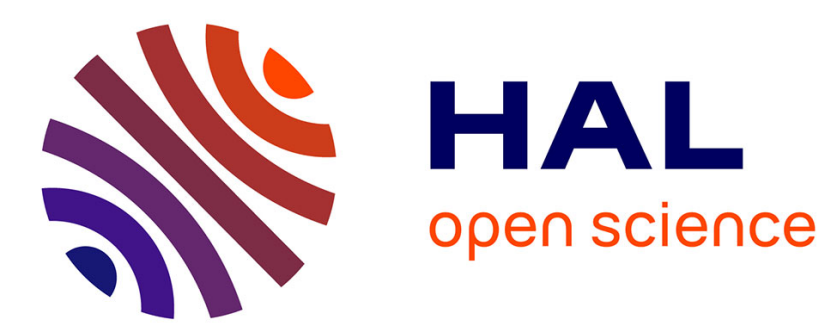

\title{
Effect of swelling on fatigue life of elastomers
}

\author{
M. S. Loo, Jean-Benoit Le Cam, Andri Andriyana, Eric Robin, J. F Coulon
}

\section{To cite this version:}

M. S. Loo, Jean-Benoit Le Cam, Andri Andriyana, Eric Robin, J. F Coulon. Effect of swelling on fatigue life of elastomers. Polymer Degradation and Stability, 2016, 124, pp.15-25. 10.1016/j.polymdegradstab.2015.12.001 . hal-01259527

\section{HAL Id: hal-01259527 https://hal-univ-rennes1.archives-ouvertes.fr/hal-01259527}

Submitted on 25 Mar 2016

HAL is a multi-disciplinary open access archive for the deposit and dissemination of scientific research documents, whether they are published or not. The documents may come from teaching and research institutions in France or abroad, or from public or private research centers.
L'archive ouverte pluridisciplinaire HAL, est destinée au dépôt et à la diffusion de documents scientifiques de niveau recherche, publiés ou non, émanant des établissements d'enseignement et de recherche français ou étrangers, des laboratoires publics ou privés. 


\title{
Effect of swelling on fatigue life of elastomers
}

\author{
M.S. Loo ${ }^{\mathrm{a}}$, J.-B. Le Cam ${ }^{\mathrm{b}}$ A. Andriyana ${ }^{\mathrm{a}}$, E. Robin ${ }^{\mathrm{b}}$, J.-F. Coulon ${ }^{\mathrm{c}}$ \\ ${ }^{a}$ Department of Mechanical Engineering, Faculty of Engineering, University of Malaya, \\ 50603 Kuala Lumpur, Malaysia \\ bUniversité de Rennes 1, Institut de Physique de Rennes UMR CNRS 6251, Campus de \\ Beaulieu, Bat. 10B, 35042 Rennes Cedex - France \\ ${ }^{c}$ ECAM RENNES - Louis de Broglie, Campus de Ker Lann - Bruz, CS 29128 - 35091 \\ Rennes Cedex 9 - France \\ *Corresponding author: AndriAndriyana. Phone: +60 37967 5254. Fax: +60 379675317. \\ Email: andri.andriyana@um.edu.my
}

\begin{abstract}
In a number of engineering applications, elastomeric components are exposed to aggressive solvent such as biodiesel. Since biodiesel is considered as a potential substitute for conventional fossil fuel, the study on the durability in service of elastomers exposed to biodiesel becomes essential. The present paper investigates the mechanical response of swollen elastomers, due to exposure to palm biodiesel, under fatigue loading conditions. To this end, fatigue tests are conducted on dry and swollen rubber specimens at various maximum strains and a zero strain ratio. The physical fatigue damage mechanism induced in swollen material is studied through FESEM analysis coupled with EDS. During the test,two definitions of specimen end-of-life are adopted: (i) the number of cycles required for a nucleated crack to reach $1 \mathrm{~mm}$ in length and (ii) the number of cycles required for a complete rupture to occur in the specimens. The fatigue lifetime curves are plotted where the maximum principal stretch is used as the predictor. It is shown that swollen rubbers have shorter lifetime compared to the dry ones. Moreover, FESEM results reveal that the swelling level has no effect on the morphology of crack nucleation and propagation, regardless of the imposed loading level.
\end{abstract}

Keywords: Elastomer, fatigue, swelling, crack nucleation, crack propagation

\section{Introduction}

In many engineering applications, elastomeric parts have to endure repetitive fluctuating loadings during the service. The ability of the parts to sustain loadings end when the component experiences rupture or fatigue failure [1] upon initiation and propagation of cracks in the material. The study of fatigue in elastomers is challenging in the mechanics of materials due to complex interactions between the matrix, fillers, plasticizers and other additives. Some of the degradation studies on elastomers under fatigue loading have already been conducted [2, 3]. Mars [4] found that elastomers underwent two distinct phases during the process of fatigue failure. The first phase is the duration of crack initiation from free observable macrocracks. This phase is followed by the propagation of the crack up to failure 
during the second phase. Hence, he categorized the approaches to predict fatigue failure through crack nucleation and crack growth analyses. Moreover, the study of fracture behavior of rubber by a few researchers [5-7] revealed that the appearance of a particular macroscopic crack was a consequence of the microscopic crack propagation initiating from the preexisting flaws in the virgin material.

Meanwhile, the awareness on the depletion of non-renewable energy sources has raised the attention of researchers to consider renewable energy sources. Along this line, palm biodiesel has been considered as a promising future fuel substitute [8-10]. Even though it possesses countless advantages, the compatibility between elastomeric components and palm biodiesel, remains as a major challenge. Indeed, it was reported that the exposure to biodiesel degrades the properties of elastomer [11-18]. One major type of degradation encountered in elastomers due to exposure to palm biodiesel is swelling [14]. While swelling is important for the durability analysis, the exact mechanism by which swelling contributes to the fatigue damage remains incompletely understood $[19,20]$. Therefore, the study on fatigue of swollen elastomers becomes essential.

The present paper investigates the effect of swelling level, due to exposure to palm biodiesel, on the fatigue life. In the following section, detailed experimental work is provided and the results are discussed including stretch-stress response, fatigue lifetime curve and FESEM analyses. Finally, concluding remarks are given at the end of the paper.

\section{Experimental programme}

\subsection{Material and specimen geometry}

The material investigated in this study is a class of nitrile rubber filled with $25 \%$ wt of carbon black. It is denoted as F-NBR in the rest of the paper. The specimens have a hollow-diablo shape with height, outer diameter, and wall thickness of $55 \mathrm{~mm}, 25 \mathrm{~mm}$, and $6 \mathrm{~mm}$, respectively. The hollow-diablo shape specimen was proposed by Beatty [21] and has been regularly used in the fatigue literatures [22-25]. Here, the hollow geometry allows a homogenous diffusion of solvent into the gauge section of rubber at relatively short period of time. The detailed features of the specimen used in the present study are provided in Fig.1.

The F-NBR rubbers were freely swollen through immersion in a palm biodiesel bath until the desired swelling levels were achieved. Three swelling levels were considered: $0 \%, 3 \%$ and $5 \%$ on the basis of volume change, which correspond respectively to no immersion (dry), 3 days and 10 days of immersion duration. No standard was used for the choice of the specimens and immersion durations. The percentage of volume change of the swollen rubber was calculated with the following equation in accordance to the ASTM D471 standard:

$$
\Delta V \%=\frac{\left(M_{3}-M_{4}\right)-\left(M_{1}-M_{2}\right)}{\left(M_{1}-M_{2}\right)} X 100
$$

where $\Delta V$ is the change in volume, $M_{1}$ is the initial mass of specimen in air, $M_{2}$ is the initial mass of specimen in water, $M_{3}$ is the mass of specimen in air after immersion, $M_{4}$ is the mass of specimen in water after immersion. 

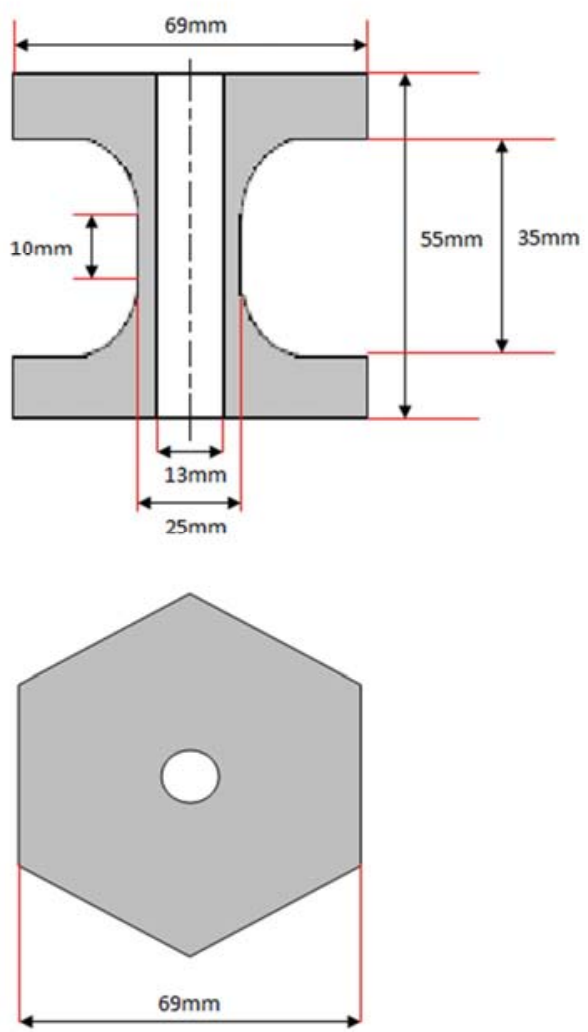

Fig.1:Geometry of rubber specimen.

The degree of swelling, $J_{\mathrm{s}}$, is defined by the ratio between the volume of swollen specimen and one of the dry specimens. Hence, the $J_{\mathrm{s}}$ values for the swelling levels of $0 \%, 3 \%$ and $5 \%$ are $1,1.03$ and 1.05 respectively. In the following sections, the swelling in rubber specimens is described in terms of the degree of swelling.

In order to verify the swelling state of the swollen rubber throughout the fatigue tests, the mass change is calculated with the following equation:

$\Delta M \%=\frac{M_{t}-M_{s}}{M_{S}} X 100$

where $\Delta M$ is the change in mass, $M_{t}$ is the mass in air of the swollen rubber after fatigue testing, $M_{S}$ is the mass in air of the swollen rubber before testing. The measured mass is in units of gramme.

In addition to the mass change, the hardness for both swollen and dry rubber is measured before and after testing in order to investigate the physical effect of different swelling levels of the rubber, through the following equation:

$\Delta H \%=\frac{H_{t}-H_{s}}{H_{s}} X 100$ 
where $\Delta H$ is the change in hardness, $H_{t}$ is the hardness value of the swollen rubber after testing, $H_{s}$ is the hardness value of the swollen rubber before testing. The hardness values are in units of Shore A hardness with an accuracy of \pm 1 Sh A.

\subsection{Uniaxial fatigue test}

The tests used Shimadzu 4830 fatigue testing machine with the maximum load cell capacity of $5 \mathrm{kN}$. The rubbers were subjected to a prescribed sinusoidal displacement at room temperature. The loading direction applied was in a uniaxial tension mode. The nominal strain ratio or loading ratio, $R_{\varepsilon}$ is defined as the ratio between the minimum strain, $\varepsilon_{\min }$ and the maximum strain, $\varepsilon_{\max } . R_{\varepsilon}$ is set to be zero throughout the experiment by imposing the maximum stretch values of 1.5,1.75, 1.9 and 2, while the minimum stretch remains zero. In the current investigation, the stretch is defined by the ratio between the current lengths to the initial length of the rubber specimen. In the case of swollen rubber, the specimen initial length corresponds to the swollen-unstressed length. Being the first approach, thermal effects were undesirable. For this purpose, the frequency imposed for all loading conditions is $1 \mathrm{~Hz}$ except for the maximum stretch of 1.5 , where a $2 \mathrm{~Hz}$ is applied. Two tests are completed for each loading condition.

\subsection{FESEM analyses}

The fracture surfaces for both dry and swollen rubber were observed with a JEOL JSM T100F Field Emission Scanning Electron Microscope (FESEM) coupled with the Energy Dispersive Spectrometer of X-rays (EDS). The EDS was used to identify the chemical elements present in the material. In order to avoid any electron charge at the surface, specimens were coated with a thin layer of gold dust by vapour deposition.

\section{Results and discussion}

In this section, the change in the physical properties of rubber is first discussed to evaluate the effects of swelling on the rubber microstructures. This is followed by the discussion on the mechanical response of rubber represented in stretch-stress plots at selected cycles to look into the effect of different swelling level. The fatigue lifetime curve is then plotted to compare the number of cycles to failure for both dry and swollen rubbers. Finally, the FESEM analyses are carried out with the intention to search for supporting results to explain the obtained mechanical responses.

\subsection{Physical properties}

The length and thickness of the middle section for swollen rubbers is measured after immersion and the ratio of these values over the dry one is plotted as a function of $J_{\mathrm{s}}$ in Fig.2. In this figure, both length and thickness increase with the swelling level. The increase in dimension from dry to swollen state, $J_{\mathrm{s}}=1.03$, is higher in thickness $(10 \%)$ as compared to in length (1\%). For higher swelling, i.e. $J_{\mathrm{s}}=1.05$, the increase become $13 \%$ and $2 \%$ respectively. 

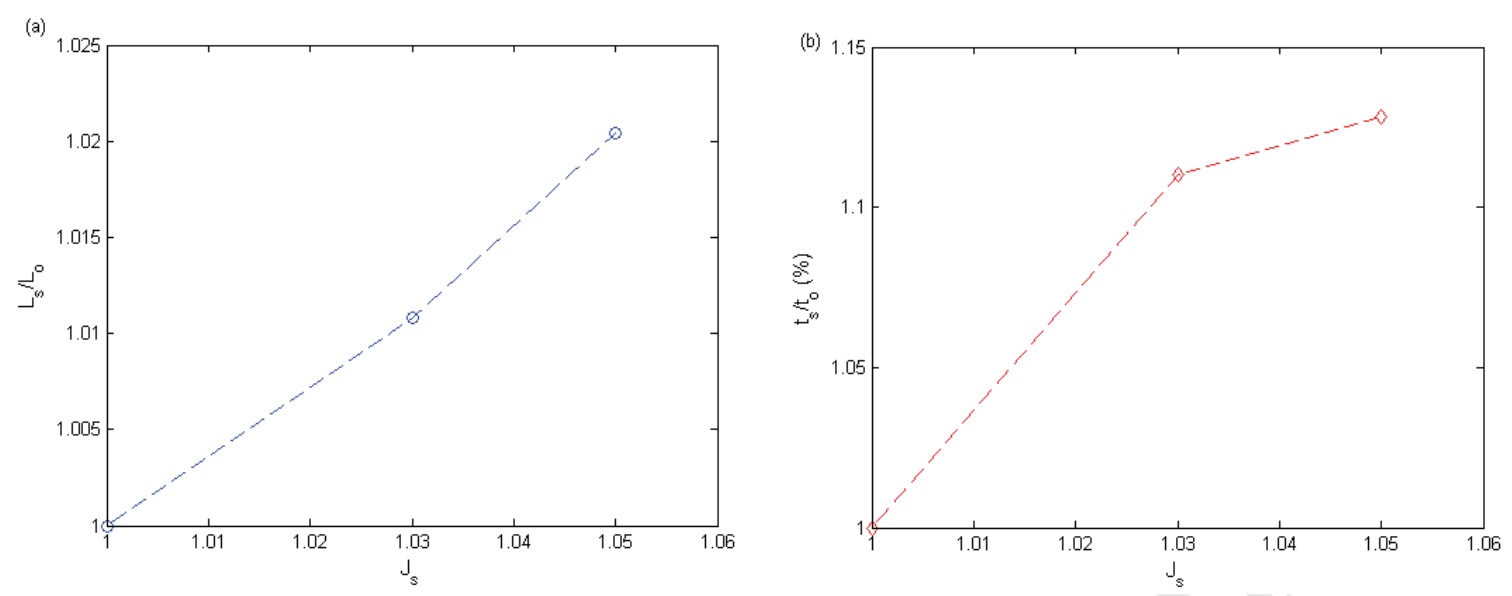

Fig.2: The ratio of swollen dimension over dry one as function of $J_{\mathrm{s}}$ for (a) length and (b) thickness. The measurement is taken in the middle section of the specimen.

The measured average hardness values for all specimens before and after testing are tabulated in Table 1 while Table 2 tabulates for mass. The changes of mass and hardness in percentage are calculated through Equation 2 and Equation 3. In these tables, the negative sign in the percentage shows that there is a decrease in hardness and mass for swollen rubber after it issubjected to fatigue testing. As indicated in Table 1, it is to note that the decrease in the hardness is already observed for swollen rubbers even before fatigue testing. This deteriorative effect on the hardness property is a direct consequence of swelling. Thedifference in the hardness value between the two swelling levels is relatively small. The slight decrease in mass for swollen rubbers $(0.3 \%)$ indicates the swollen state at the assigned degree of swelling is retained with no significant amount of liquid secreted out.

Table 1: Average and change of hardness value for dry and swollen rubber.

\begin{tabular}{|l|c|c|c|}
\hline \multicolumn{1}{|c|}{ Rubber } & Before testing (Sh A) & After testing (Sh A) & $\Delta H \%$ \\
\hline Dry & 59.5 & 59.0 & -0.8 \\
\hline Swollen B100, Js: 1.03 & 54.79 & 48.53 & -11.4 \\
\hline Swollen B100, Js: 1.05 & 54.73 & 48.62 & -11.0 \\
\hline
\end{tabular}

Table 2: Average and change of mass value for dry and swollen rubber.

\begin{tabular}{|l|c|c|c|}
\hline Rubber & Before testing (g) & After testing (g) & $\Delta M \%$ \\
\hline Dry & 127.25 & 127.24 & 0 \\
\hline Swollen B100, Js: 1.03 & 129.71 & 129.30 & -0.3 \\
\hline Swollen B100, Js: 1.05 & 131.36 & 130.86 & -0.38 \\
\hline
\end{tabular}

\section{Remark 1:}

The evolution of $\left(\mathrm{L}_{s} / \mathrm{L}_{0}\right)$ as a function of $J_{\mathrm{s}}$ depicted in Fig. 2(a) can be described by an explicit relation of the form:

where $\mathrm{n}=2.75$.

$$
\frac{L_{s}}{L_{0}}=\left(J_{s}\right)^{1 / n}
$$




\section{Remark 2:}

According to Chai et al. [18], the NBR swollen up to 5\% and 7\% are far from equilibrium swelling. Thus, solvent distribution at this two swelling levels across cross-sections of the specimen is not homogeneous; i.e. there exists a concentration gradient through the sample thickness and the mass gain is controlled by diffusion process. Considering that the thickness of the gauge section is the thinnest, it is possible that at this section, the solvent concentration is uniform for the two swelling levels studied. This scenario is consistent with the fact that hardness for the two swelling levels is nearly identical before and after the fatigue tests.

\subsection{Stretch-stress plot}

The general mechanical response at each cycle for both dry and swollen rubber is ascertained to be comparable at each loading condition. Consequently, only stretch-stress plots at two selected cycles (the $10^{\text {th }}$ and the $100^{\text {th }}$ ) are shown in Fig. 3 for selected loading conditions. Two main points are given to explain the results. Firstly, the stress decreases as the number of cycles increase for both dry and swollen rubber regardless of the imposed maximum stretch. This is due to the softening effect and the exact physical mechanism to interpret it is currently under investigations of researchers. Some of the phenomena proposed in the reported works are: irreversible breakage of polymer chains or crosslinks in the elastomer network [4], interactions between fillers and rubber matrix, the reorganization of the filler network and the viscoelasticity of the macromolecular network in the rubbery state. Secondly, a lower mechanical response was observed in swollen rubbers. This is due to the degradation of properties of the elastomer as a result of exposure to biodiesel and it has already been reported in a number of works [14, 18, 26].

On the other hand, it appears that the mechanical response between dry and swollen rubber becomes closer as the imposed maximum stretch is higher at a given number of cycles (see Fig. 3e and f). Horkay and Lin [27] have noted that the modulus or stiffness of a swollen polymer network is not sensitive to the interaction between the polymer and the solvent, but it is governed by the concentration of network chains. Since swelling increases the volume of the rubber, the number of the molecular chains per unit volume decreases. Consequently, the energy per unit volume needed to deform the swollen rubber decreases and this is especially true for the case of lower stretch values. For instance, in Fig. 3a and $\mathbf{b}$, a significantly lower stress value is needed to stretch the specimen compared to the dry state at $\lambda=1.5$, while the amount of stress needed to stretch the rubber at $\lambda=2$ in Fig. $3 \mathbf{e}$ and $\mathbf{f}$ is similar for both dry and swollen rubber. At higher stretch values, it appears that the dominant effect on the stiffness of swollen rubber is attributed to the extensibility of the polymer chains, instead of swelling. This might be related to the similar response for both dry and swollen rubber at higher stretches and the trend is also observed for the stretch-stress response at the crack initiation, $N_{i}$, cycles in Fig. 4. Even though the $N_{i}$ is different for both swollen and dry rubber, the stretch-stress response is almost identical at the stretch value of 2. 

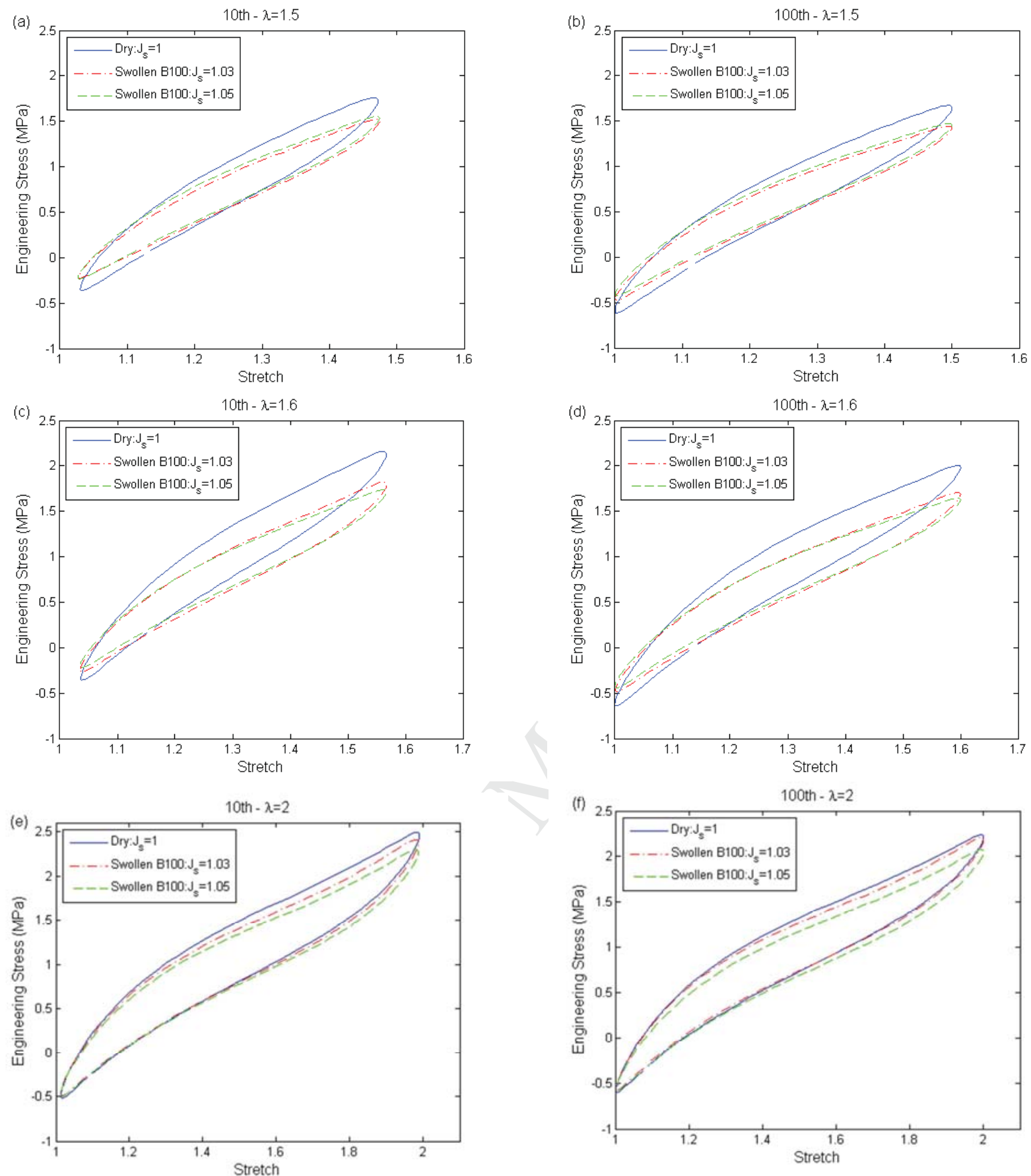

Fig.3: Stretch-stress plot for dry and swollen rubber at the tenth and hundredth cycles. 

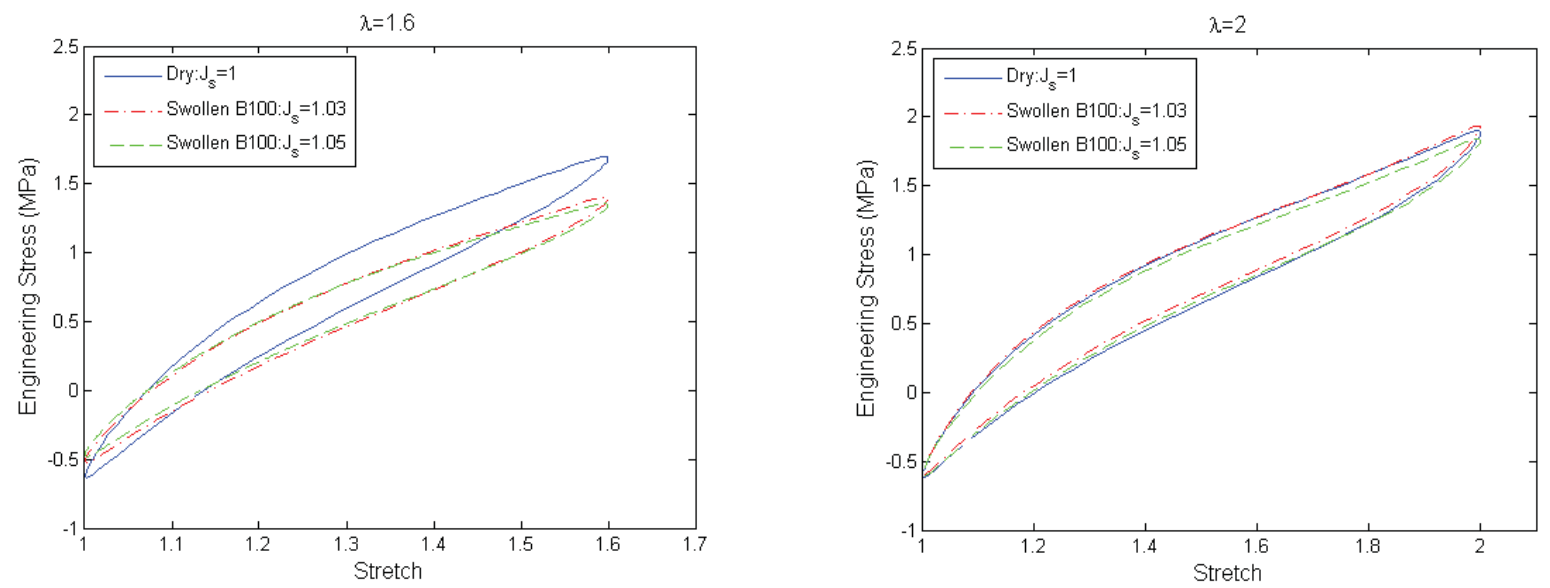

Fig. 4: Stretch-stress plot for dry and swollen rubber at the crack initiation, $N_{i}$, cycles.

\subsection{Evolution of the peak engineering stress}

In order to investigate the evolution of stress for the dry and swollen rubber, the peak engineering stress is plotted as a function of number of cycles in Fig. $\mathbf{5}$ for all specimens. At the beginning of the test, the particular fluctuations peak stress for the first few cycles are the direct consequence of the machine limitation which is unable to reach the imposed maximum stretch from the very first cycle. Subsequently, the stress values decrease progressively throughout the test before rupture, where a sharp drop takes place. The stress evolution in Fig. 5 is in the same trend with the responses obtained from the quasi-static loading shown in Fig. 3 (shorter cycles) where the responses for dry and swollen rubber are closer at higher stretches.

In this investigation, none of the curves showed a constant semi-logarithmic rate of stress decrease along the number of cycles. Other reported works identified a particular stabilized response (plateau) at certain number of cycles $[4,28]$. For instance, at the number cycles of 128 in the renowned work of Mars [4]. He proposed that this plateau at 128 cycles to be used as a reference point in order to estimate the lifetime of the material from a stabilized mechanical response. Such an approach could not be adapted in this work since no plateau was observed. 

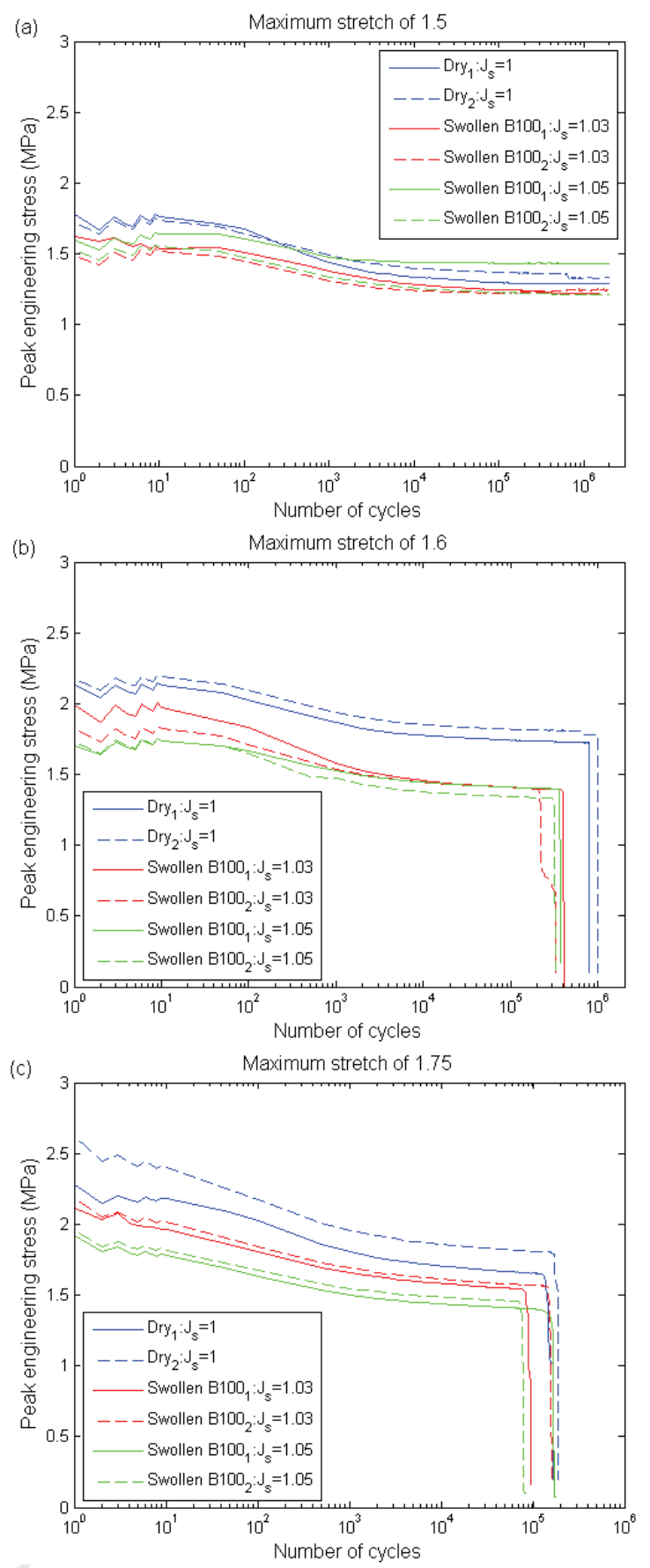

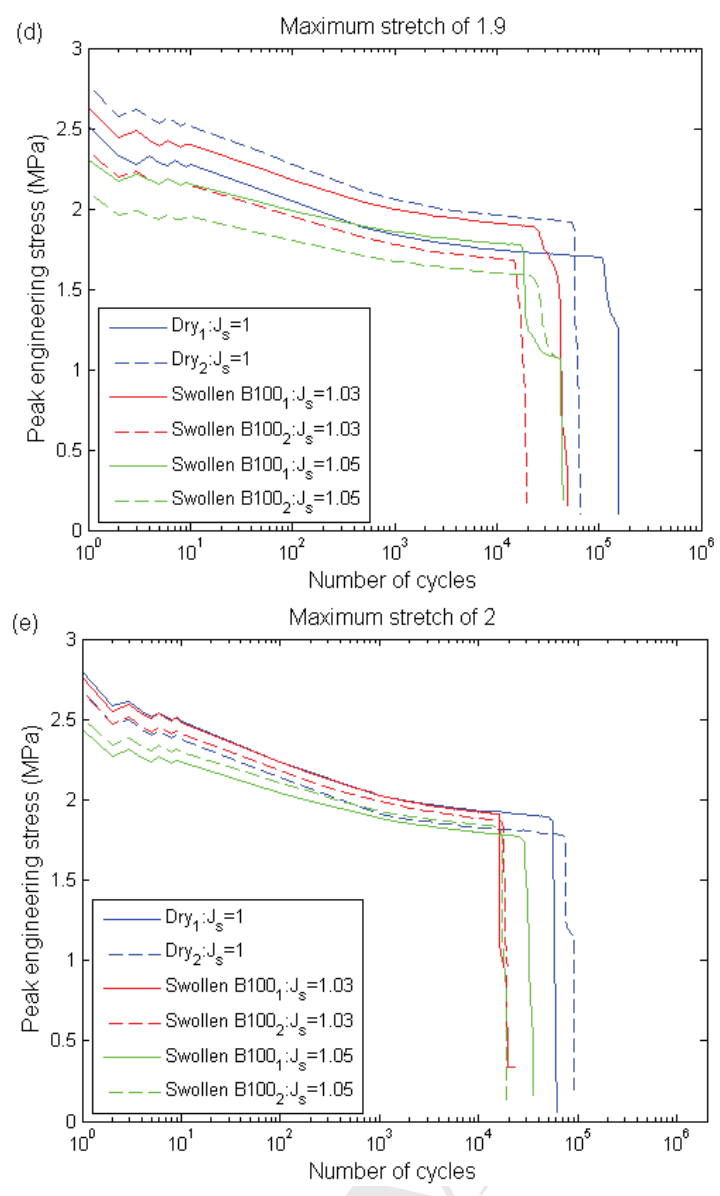

Fig.5: Evolution of peak engineering stress as a function of number of cycles.

\subsection{Fatigue lifetime}

In general, the fatigue lifetime curve is plotted using a chosen fatigue predictor as a function of number of cycles at end-of-life. Many predictors have been proposed in the literature [29]. In the present work, the maximum stretch is selected. The maximum principal stretch ratio or strain was firstly used by Cadwell [1] and has been widely used as a predictor for uniaxial fatigue [30-33]. Concerning the end-of-life, two definitions are adopted: (1) the number of cycles required for a crack to nucleate up to a size of $1 \mathrm{~mm}$ and (2) the number of cycles required for complete rupture to occur. Fig. 6 and Fig. 7 illustrate the $\lambda-\mathrm{N}$ curve plotted for both definitions of end-of-life. In both of these figures, the best power law fit to predict the lifetime is also included for both dry and swollen rubbers.

In Fig. 6, it is observed that the dry rubber has the longest lifetime for a crack to nucleate up to $1 \mathrm{~mm}$ at all loading levels. On the other hand, the lifetime for swollen rubber seems to be dependent on the swelling level and also the loading level. At lower imposed maximum stretch value of 1.75, the lifetime of swollen rubber appears to be closer to the dry rubber when compared to a higher imposed maximum stretch value. The lifetime of the $5 \%$ swollen rubber seems to be the shortest, similar and longer at the imposed stretch of 1.75, 1.9 and 2 respectively when compared to the 3\% swollen rubber. Later, Fig. 7 shows the transition of lifetime at complete rupture appears to be relatively similar for the swollen rubber even though at different swelling level. These discrepancies seem to indicate that even though the 
swelling level influences the duration of crack initiation (see Fig. 6), it does not affect significantly the crack propagation duration. This means that only two curves could be plotted in the diagram in Fig. 7; one for non-swollen and one for the range of swelling levels between $3 \%$ and $5 \%$.

Overall, the fatigue lifetime of the swollen rubber is lower than the dry one. Two ways are possible in explaining the reduction of fatigue lifetime: chemical modifications due to interaction of rubber-solvent and by considering that the swollen state is like a pre-stretched state. In our opinion, the former could lead to two consequences: (1) modification/degradation of the mechanical and physical properties of rubber and (2) acceleration of damage occurrence in the materials due to fatigue loading, i.e. coupling between chemical and mechanical processes.

Referring to Fig. 2, the swelling levels of $3 \%$ and $5 \%$ correspond to pre-stretches of approximately $\lambda=1.012$ and $\lambda=1.020$ respectively. For rubber, these stretch levels are relatively small. Recalling that the fatigue lifetime of swollen rubber is found to be significantly shorter than that of dry rubber, it appears that it is not sufficient to consider prestretched state alone as the main cause of this significant lifetime reduction. This observation suggests that chemical modifications have taken place when the NBR is exposed to palm biodiesel. In this case, the diffusion process occurs promptly owing to their favorable polarity state. The absorption of biodiesel leads to the extraction of the existing stabilizers and, hence, accelerating the chemical alteration process in the rubber [11, 12, 34]. The chemical oxidation that takes place through the chain scission mechanism has been reported in a number of works [12, 13, 34]. Furthermore, by comparing the shear modulus of dry NBR and that of NBR swollen by palm biodiesel, it was shown in Chai et al [15] that the shear modulus of swollen NBR deviates from the concept of interdiffusion of Treloar [35], which implies that chemical interactions between NBR and palm biodiesel has indeed taken place. 


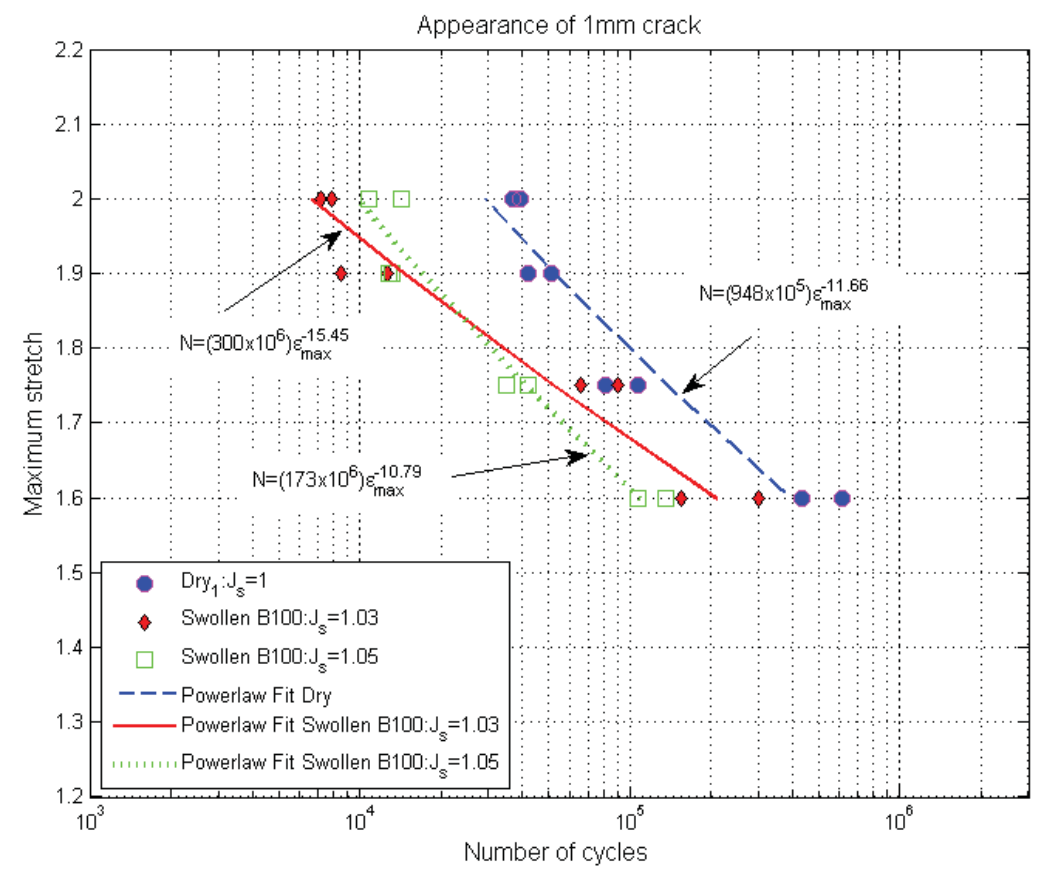

Fig. 6: Maximum stretch versus cycles to appearance of $1 \mathrm{~mm}$ crack for dry and swollen rubber.

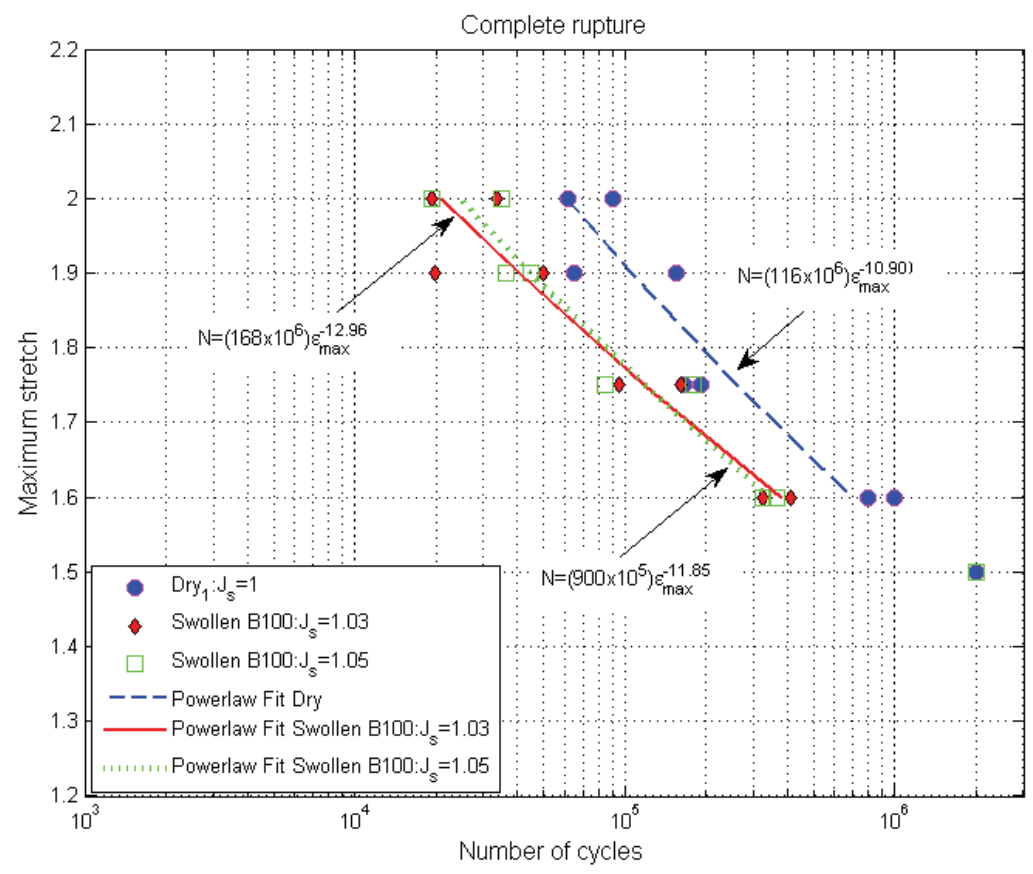

Fig. 7: Maximum stretch versus cycles to complete rupture for dry and swollen rubber.

\subsection{FESEM observations}




\subsubsection{Analysis at macroscopic scale}

An example of ruptured dry rubber specimen is shown in Fig. 8. It is to note that these features are relatively similar to swollen rubber regardless of the loading level. In this figure, theg enerated crack propagation plane is circled in red solid line. It is observed that the crack propagation plane is not perpendicular to imposed loading. This observation could be related to the hollow geometry of the specimen, which induces a complex crack propagation direction. At this plane, investigations are carried out at the microscopic scale to observe the morphologies of crack nucleation location and crack propagation.

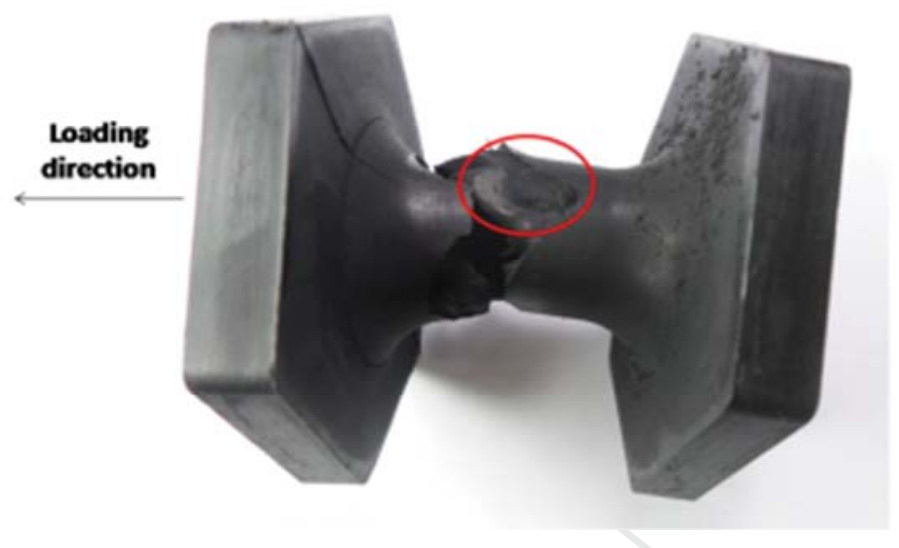

Fig. 8: Ruptured dry specimen.

\subsubsection{Analysis at microscopic scale}

At this scale, the analysis is performed through FESEM to first compare the rubber surface at the dry un-stressed and swollen un-stressed state. The observed surfaces were obtained by cutting at the middle section of the un-stressed specimens with a razor blade. Fig. 9 and 10 shows the micrographs obtained at the surface for dry and swollen rubber (B100) respectively. 

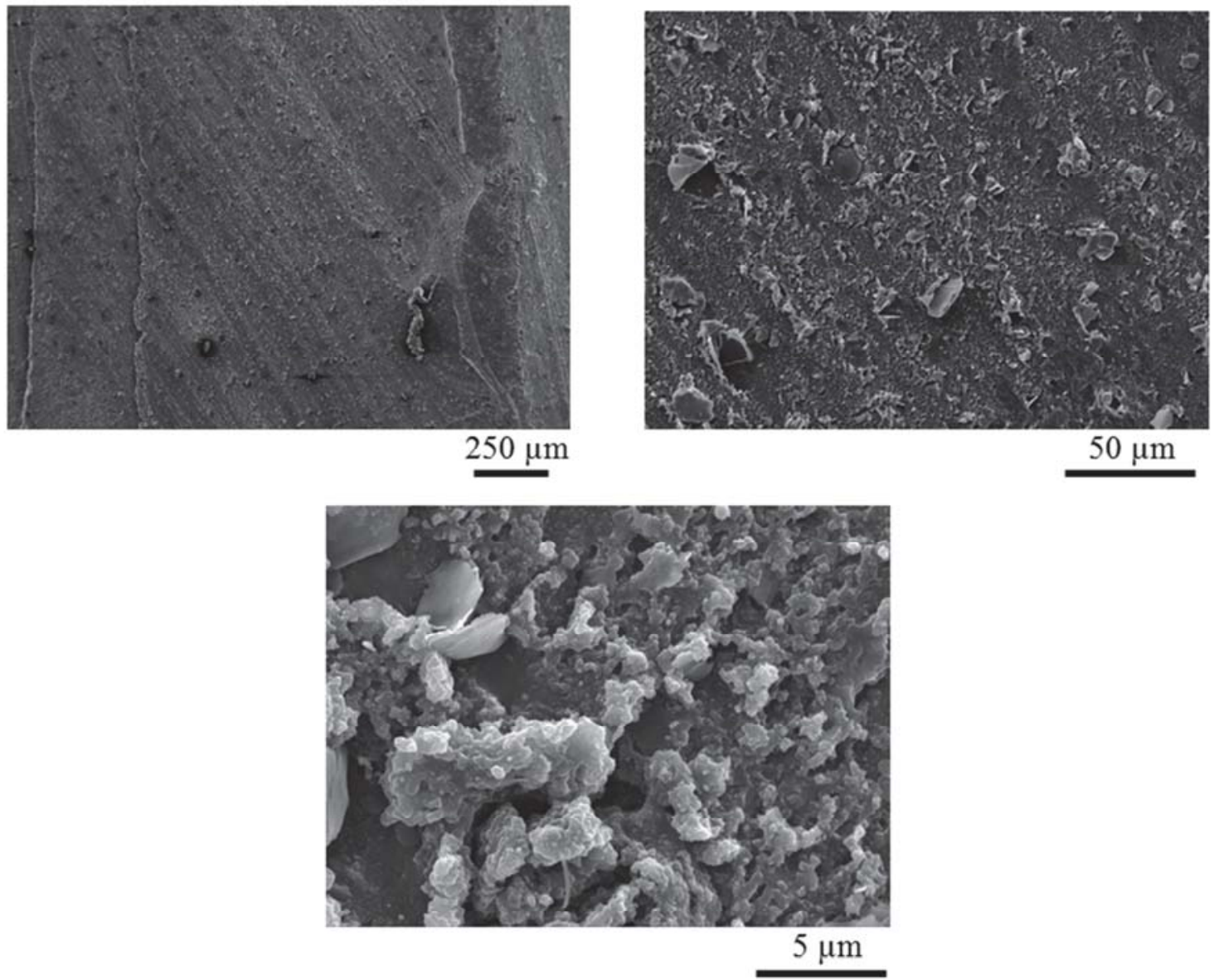

Fig. 9: Surface of dry rubber. 


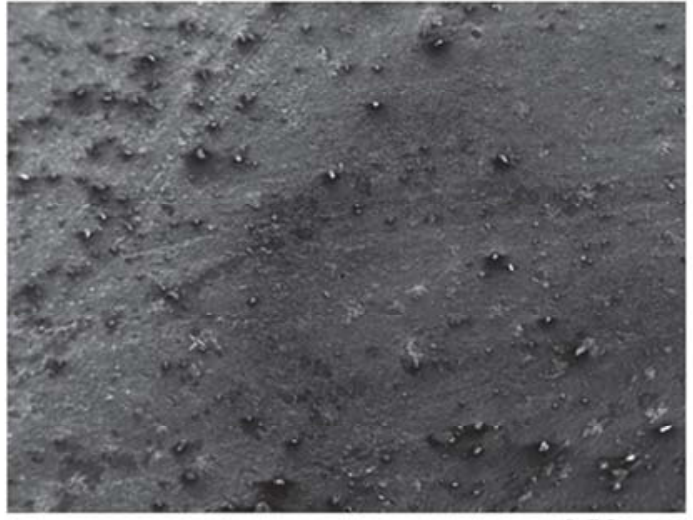

$250 \mu \mathrm{m}$

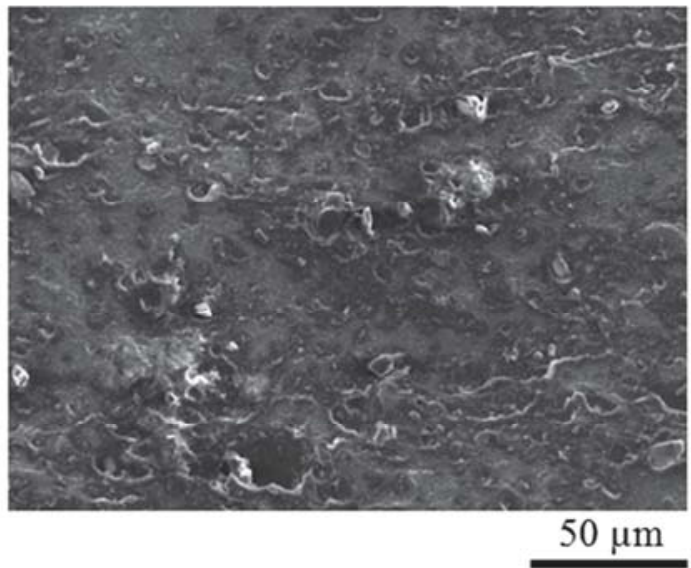

$50 \mu \mathrm{m}$

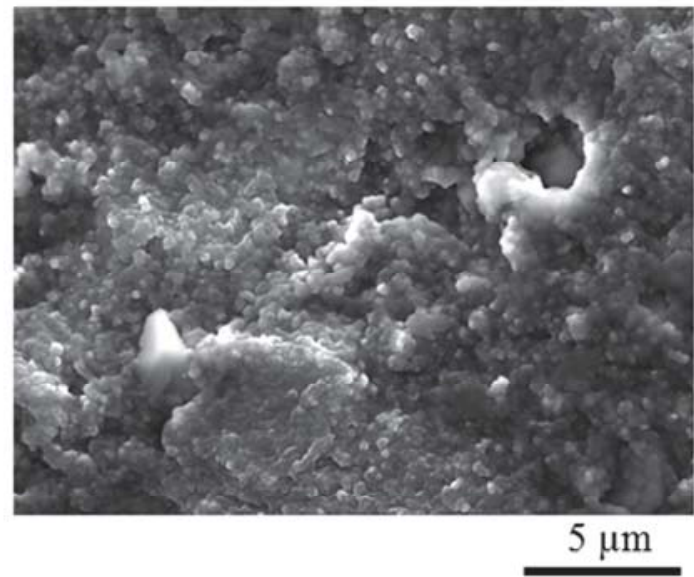

Fig. 10: Surface of swollen B100 rubber.

Generally, the surface of the swollen B100 rubber appears to be smoother than the dry rubber. Besides that, a huge amount of particles seem to be present throughout the swollen rubber surface, seen at 50X magnification. Indeed, exposure of rubber to biodiesel may induce extraction of soluble components from the rubber [11, 34].

The next step includes identifying precisely the crack nucleation location and origin after completing the fatigue tests from post-mortem analyses. Moreover, the crack propagation characteristics are also studied. Therefore, the discussion for the obtained results is detailed in two categories, the crack nucleation and crack propagation.

\section{(i) Crack nucleation}

The current existing thorough studies for crack nucleation is in dry filled natural rubber [5-7, 25] and dry filled styrene butadiene rubber [36]. Only one study has been reported for filled dry and swollen nitrile rubber [26]. In the dry filled natural and styrene butadiene rubbers, the crack nucleates about $300 \mu \mathrm{m}-400 \mu \mathrm{m}$ from the fracture specimen surface. The source of the crack was found to be material flaws such as carbon black agglomerate failures, concentration of cavities and cavitation at particle poles. The results obtained in nitrile rubber contradict from these findings. The analyzed fracture surface of a dry nitrile rubber specimen reveals that the crack nucleates at the surface of the specimen instead at the subsurface. Furthermore, it is deduced that the stress concentration is highest at this site since no particles or agglomerates were observed. It is worth noting that all observations performed by the authors at this site appeared to be similar for both 
dry and swollen rubber regardless of the loading condition. No significant difference has been identified in the location and origin of the crack nucleation of between $3 \%$ and $5 \%$ swelling.

(ii) Crack propagation

Similar patterns have been observed in the crack propagation sites for dry, 3\% swollen and 5\% swollen rubber. A particular feature named in the present study as clouded wool (CW) in [26] is recognized, appearing at the crack propagation site. Fig. 11 shows that $\mathrm{CW}$ was observed in a dispersed or cluster form for the both of swelling levels (see circled zone in the white dashed line). These CWs are observed in dry and swollen rubber. The micrograph of a higher magnification on one of the CW from Fig. 11 (a) is shown in Fig. 12. From here, the identification of the elements present in CW was performed through the EDS and the result revealed that the carbon element was found to be the main constituent of $\mathrm{CW}$. Meanwhile, no visible bonding between the $\mathrm{CW}$ and the rubber matrix is observed. The CW seems to be formed due to the friction of the two generated fracture surfaces before being dispelled towards the crack nucleation site. Their shape and location does not differ between dry and swollen specimen. Consequently, CW does not enable us to observe any swelling level effect on the crack propagation phase. Other common feature such as river patterns were observed at the surface of all specimens. Smooth surface are only observed in swollen rubber and it is present either in scattered (see circled zone in the white dashed line) or patches as shown in Fig. 13 (a) and Fig. 13 (b) respectively. The presence of CW does not appear according to the type of loading conditions nor the swelling level. A higher magnification micrograph in Fig. 13 (c) reveals that the swelling is non-homogenous in the rubber. 


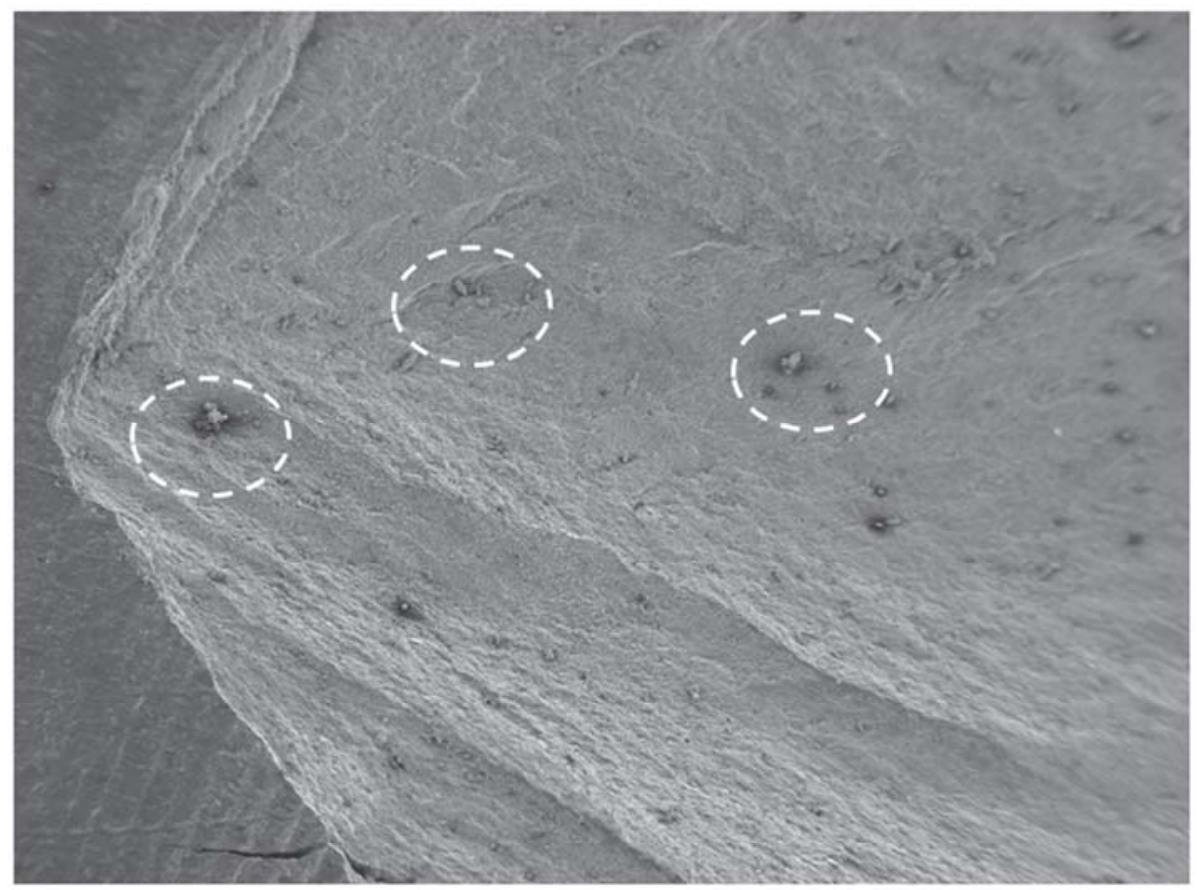

$250 \mu \mathrm{m}$

(a) Dispersed.

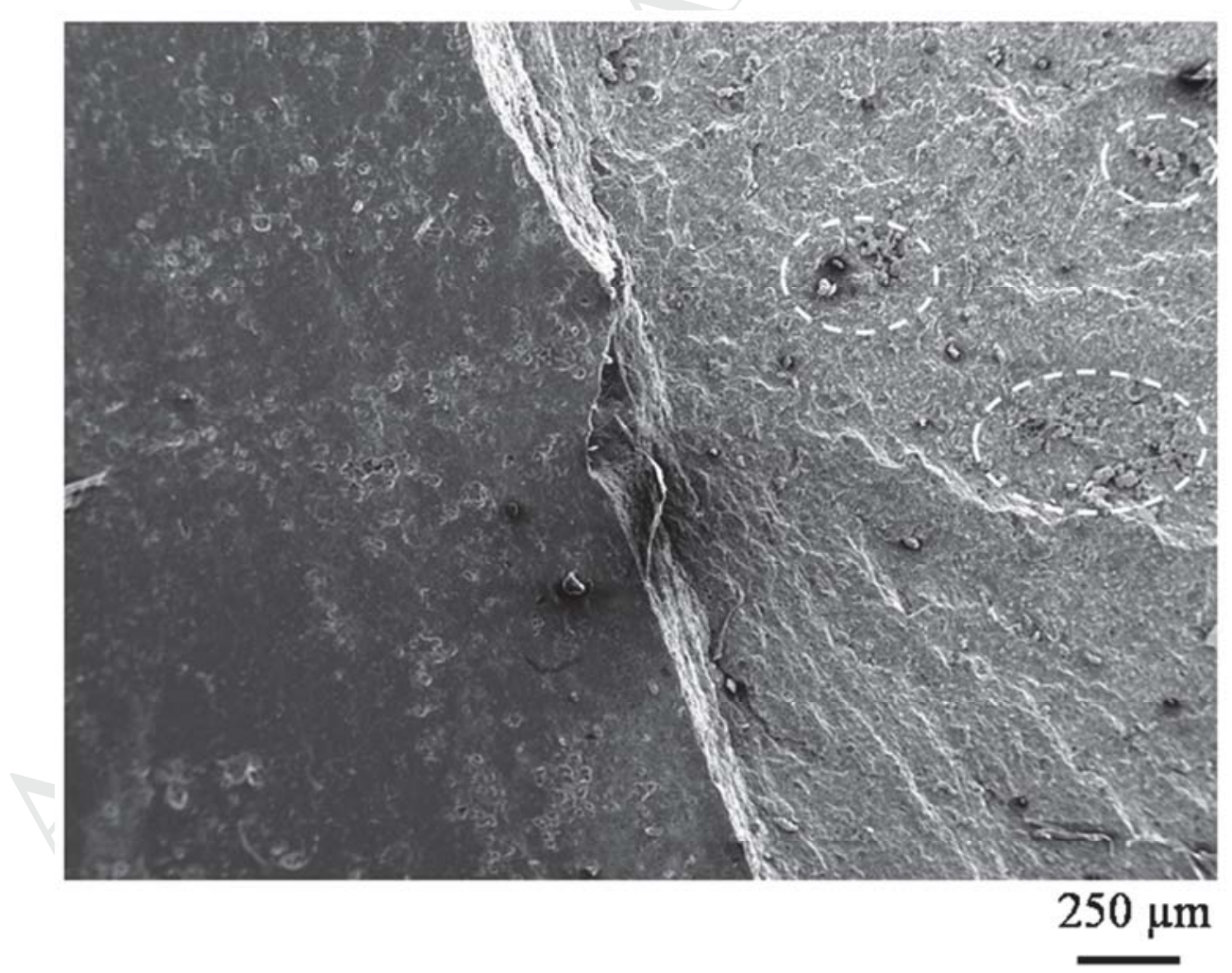

(b) Clusters. 


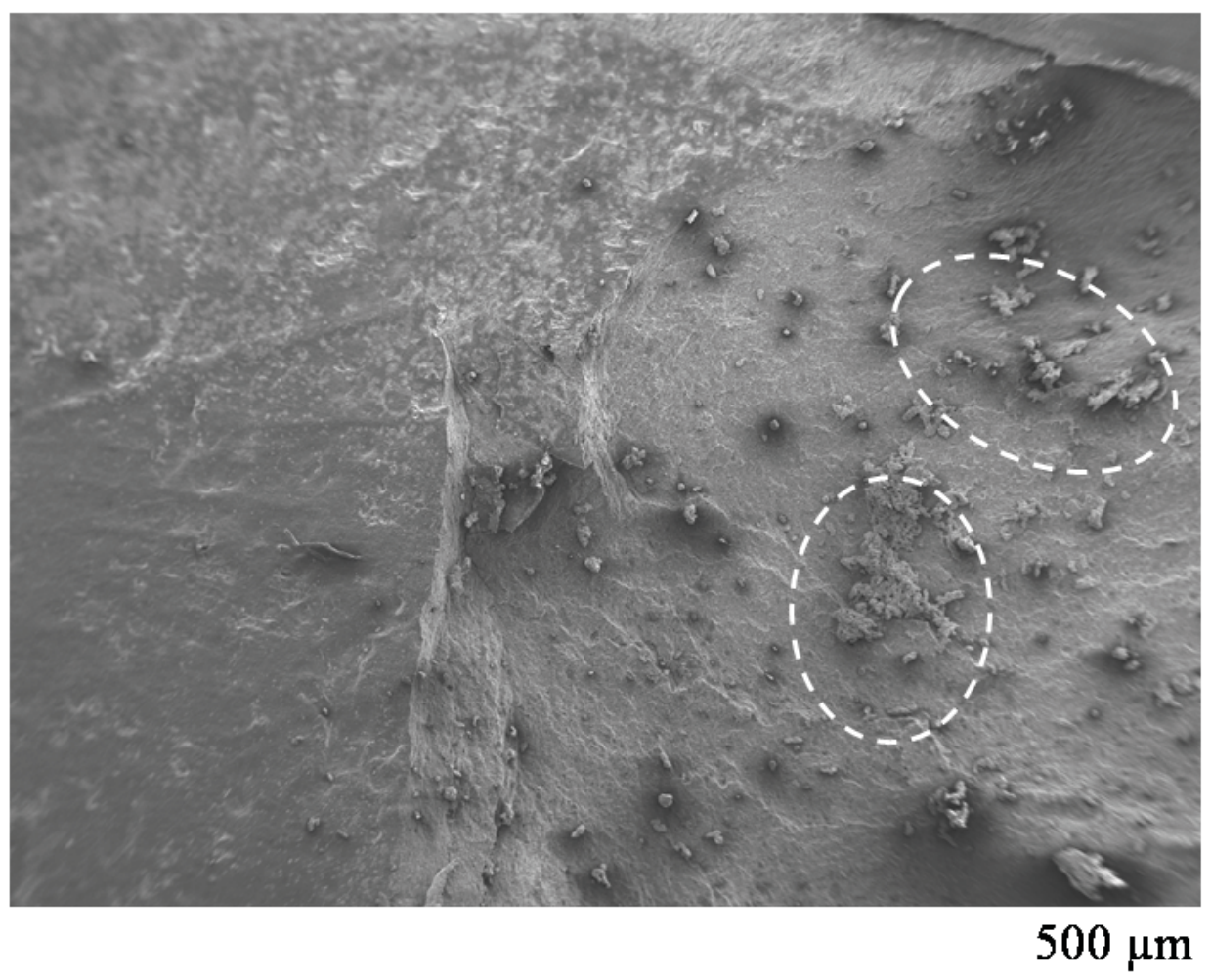

(c) Dispersed and clusters.

Fig. 11: Forms of clouded wool (CW) at the crack propagation site in (a) dry rubber (b) 3\% swollen rubber (c) 5\% swollen rubber.

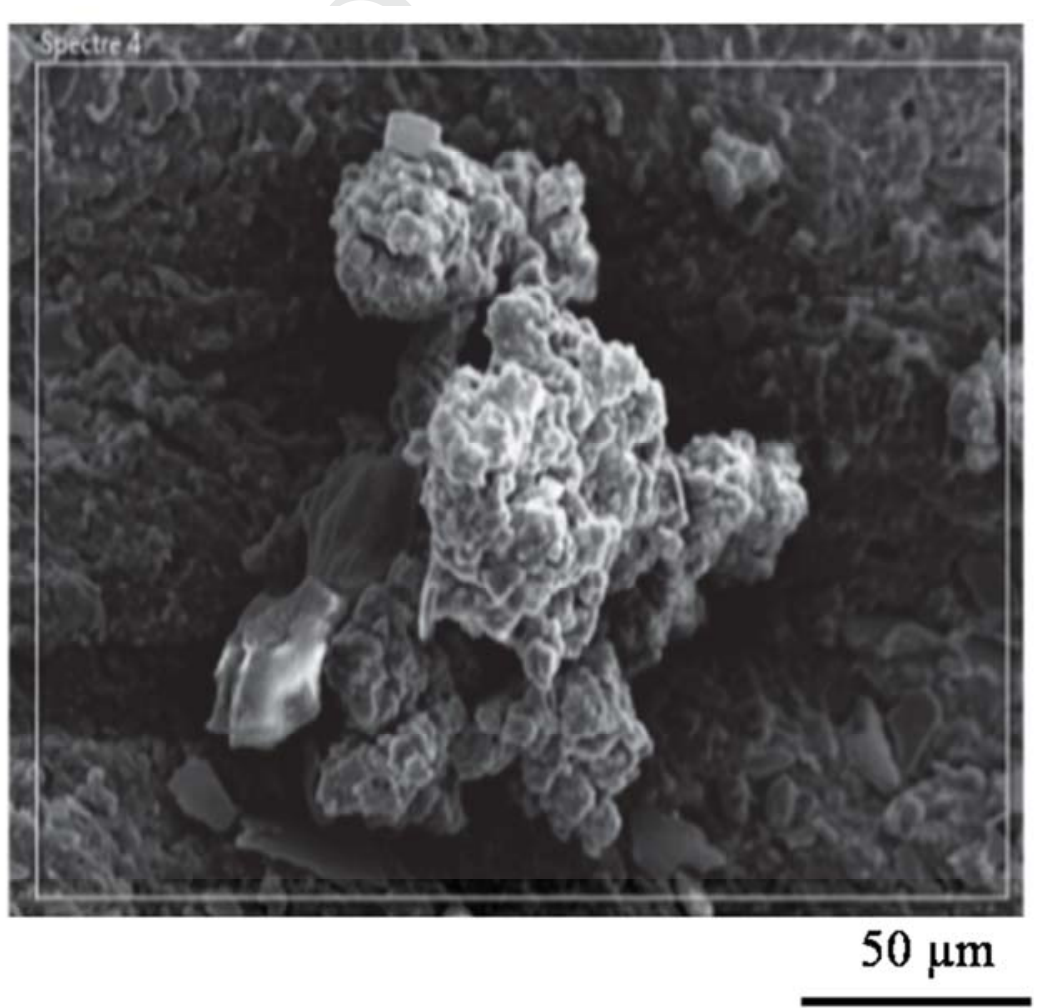

Fig. 12: Higher magnification of clouded wool. 
(a)

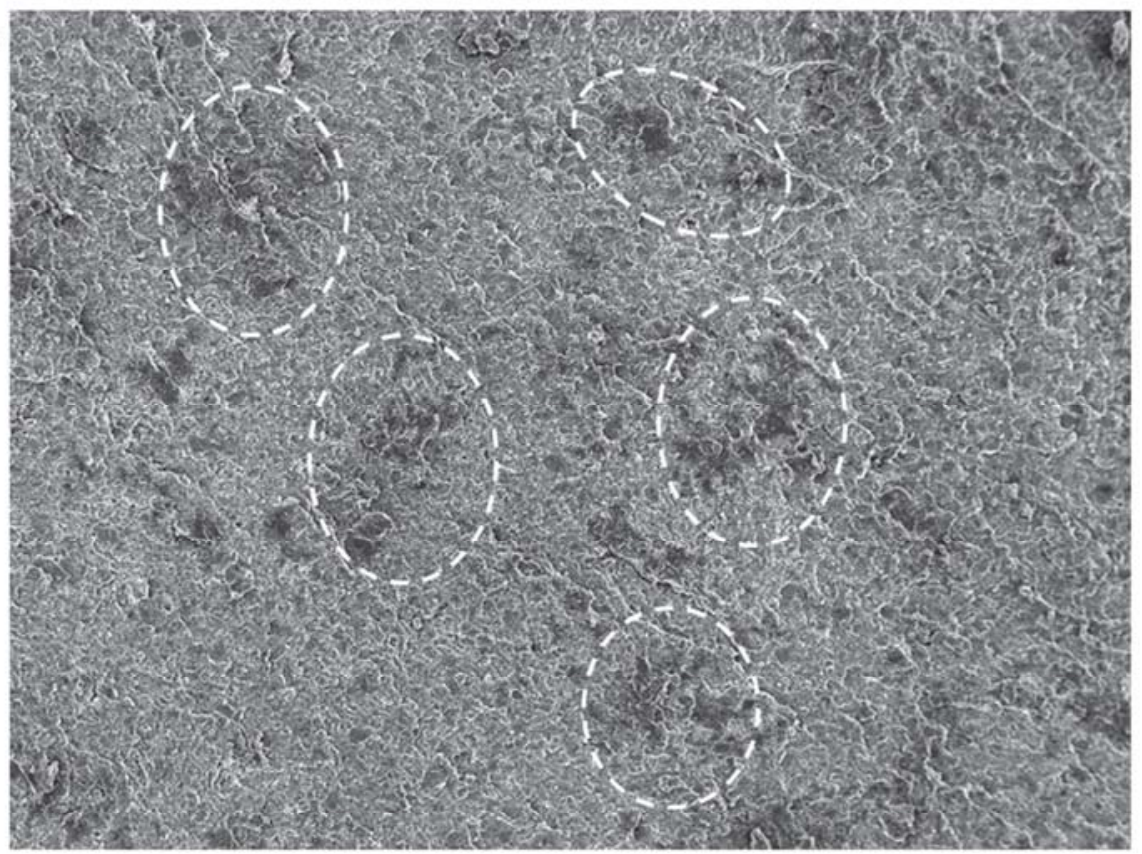

$250 \mu \mathrm{m}$

(b)

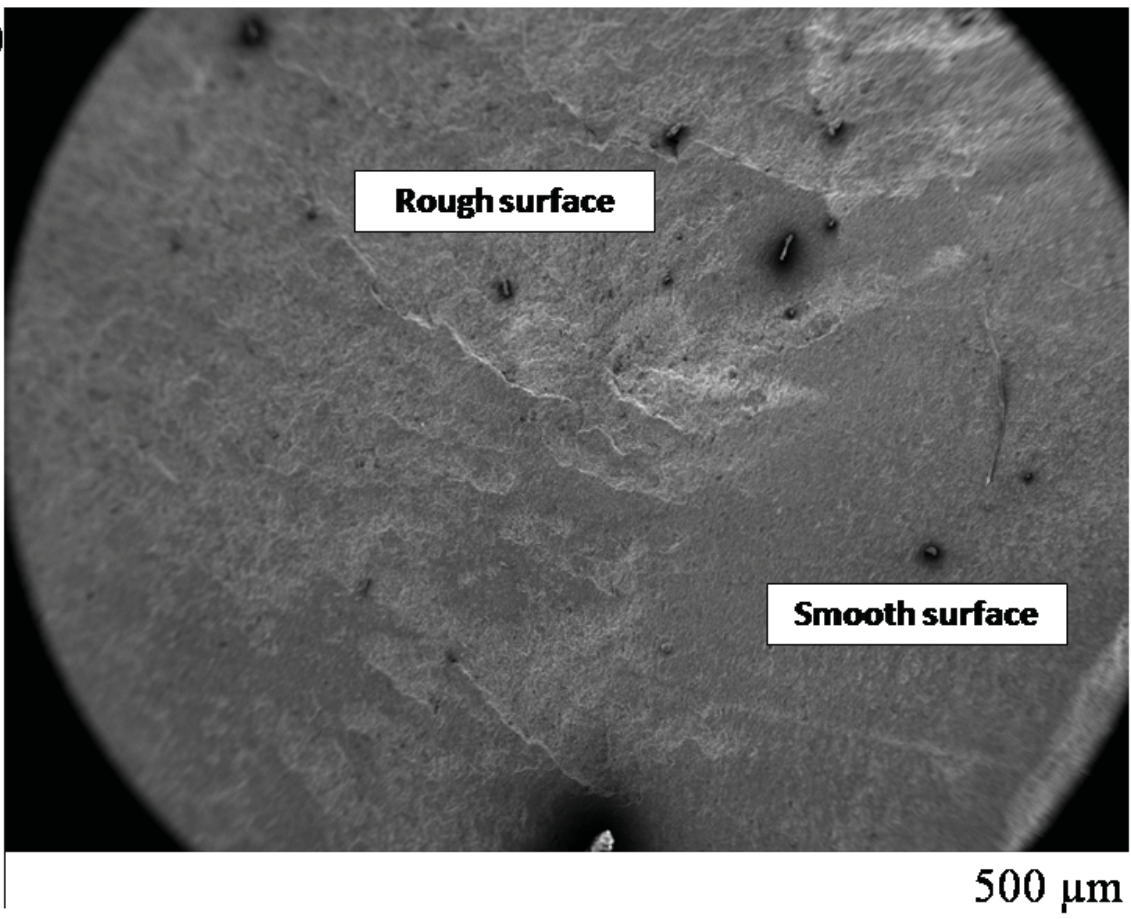


(c)

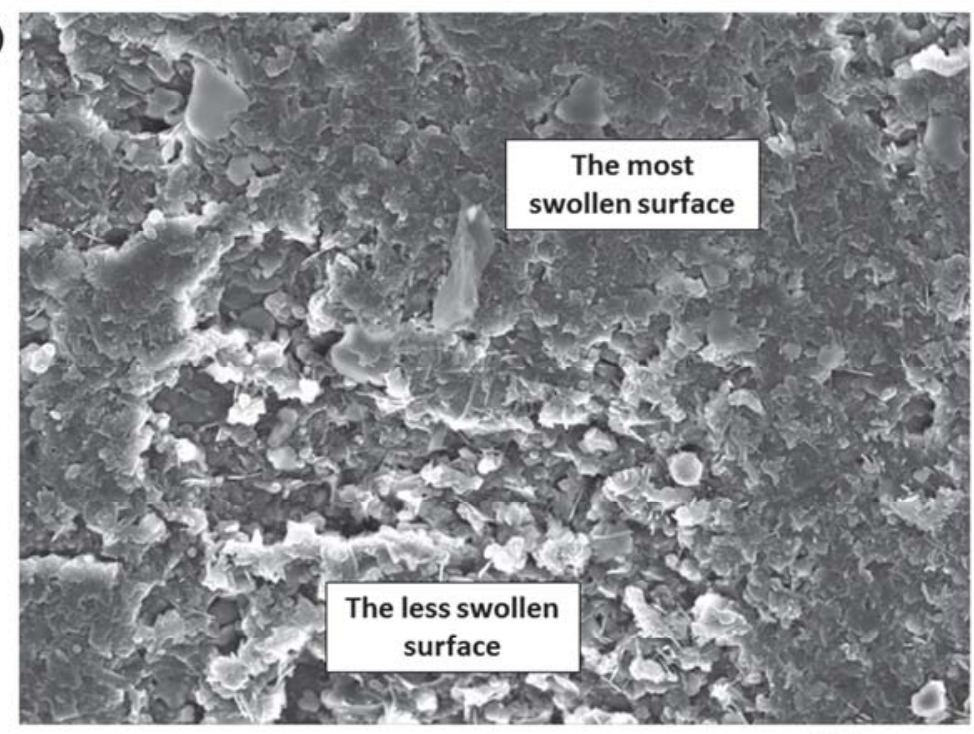

$50 \mu \mathrm{m}$

Fig. 13: Smooth surfaces appearing in swollen rubber. (a) Scattered. (b) Patches.

(c) Non-homogeneous swelling.

After investigating the crack nucleation and propagation zone at both microscopic and macroscopic scales, it can be deduced that no deviation of pattern and crack morphologies was observed, regardless of the swelling level of rubber. Furthermore, the effect of different swelling levels does not develop any particular combination characteristic with different imposed maximum stretch loading onto the rubber.

\section{Conclusion}

The effect of swelling level on the nitrile rubber under uniaxial fatigue loading has been investigated. The lifetime of the swollen rubber is generally shorter than the dry rubber regardless of the type of imposed maximum stretch value. However, the swelling level might induce an effect when the crack nucleates up to a certain size, which is $1 \mathrm{~mm}$ for this case. On the other hand, no significant difference is observed in the fractography analysis at the macro and microscale scales for both dry and swollen rubber, at the crack initiation and propagation zone. Even though crack initiates at the specimen surface, it is found that the crack nucleation pattern is not distinguishable for all investigated specimens. In fact, the effect of loading on the morphology of cracks is not noticeable on all of the fracture surface specimens. Future works on the study of the influence of different loading ratios and formulations on swollen rubber should be considered in order to understand further the behavior of rubber under fatigue condition.

\section{Acknowledgement}

The authors greatly appreciate the financial support of the Ministry of Higher Education Malaysia through High Impact Research Grant MOHE-HIR D000008-16001, University of 
Malaya (UM). The present work is also partially funded by University of Malaya Research Grant UMRG RP022B-13AET and by the Embassy of France in Malaysia. Loic Joanny and Francis Gouttefangeas are acknowledged for SEM images and EDS analyses performed at CMEBA (ScanMAT, University of Rennes 1).

\section{References}

[1] S. Cadwell, R. Merrill, C. Sloman, F. Yost, Dynamic fatigue life of rubber, Industrial \& Engineering Chemistry Analytical Edition, 12 (1940) 19-23.

[2] S.R. Dixon, A.J. Hill, J.A. O'Donnell, The effect of cyclic stress on the enthalpy relaxation behaviour of thermophysically aged unplasticised poly (vinyl chloride), Polym. Degrad. Stab., 89 (2005) 208219.

[3] Q.-Z. Fang, T. Wang, H. Beom, H. Li, Effect of cyclic loading on tensile properties of PC and PC/ABS, Polym. Degrad. Stab., 93 (2008) 1422-1432.

[4] W.V. Mars, Multiaxial Fatigue of Rubber, PhD Thesis, University of Toledo, (2001).

[5] W. Mars, A. Fatemi, Fatigue crack nucleation and growth in filled natural rubber, Fatigue \& Fracture of Engineering Materials \& Structures, 26 (2003) 779-789.

[6] J.-B. Le Cam, B. Huneau, E. Verron, Description of fatigue damage in carbon black filled natural rubber, Fatigue \& Fracture of Engineering Materials \& Structures, 31 (2008) 1031-1038.

[7] J.-B. Le Cam, B. Huneau, E. Verron, Fatigue damage in carbon black filled natural rubber under uni-and multiaxial loading conditions, International Journal of Fatigue, 52 (2013) 82-94.

[8] E. Akbar, Z. Yaakob, S.K. Kamarudin, M. Ismail, J. Salimon, Characteristic and composition of Jatropha curcas oil seed from Malaysia and its potential as biodiesel feedstock feedstock, European journal of scientific research, 29 (2009) 396-403.

[9] A. Abdullah, B. Salamatinia, H. Mootabadi, S. Bhatia, Current status and policies on biodiesel industry in Malaysia as the world's leading producer of palm oil, Energy Policy, 37 (2009) 5440-5448. [10] I. Mukherjee, B.K. Sovacool, Palm oil-based biofuels and sustainability in southeast Asia: A review of Indonesia, Malaysia, and Thailand, Renewable and Sustainable Energy Reviews, 37 (2014) $1-12$.

[11] W. Trakarnpruk, S. Porntangjitlikit, Palm oil biodiesel synthesized with potassium loaded calcined hydrotalcite and effect of biodiesel blend on elastomer properties, Renewable Energy, 33 (2008) 1558-1563.

[12] A.S.M.A. Haseeb, H.H. Masjuki, C.T. Siang, M.A. Fazal, Compatibility of elastomers in palm biodiesel, Renewable Energy, 35 (2010) 2356-2361.

[13] A.S.M.A. Haseeb, T.S. Jun, M.A. Fazal, H.H. Masjuki, Degradation of physical properties of different elastomers upon exposure to palm biodiesel, Energy, 36 (2011) 1814-1819.

[14] A. Andriyana, A.B. Chai, E. Verron, M.R. Johan, Interaction between diffusion of palm biodiesel and large strain in rubber: Effect on stress-softening during cyclic loading, Mechanics Research Communications, 43 (2012) 80-86.

[15] A.B. Chai, A. Andriyana, E. Verron, M.R. Johan, A.S.M.A. Haseeb, Development of a compression test device for investigating interaction between diffusion of biodiesel and large deformation in rubber, Polymer Testing, 30 (2011) 867-875.

[16] S.Y. Ch'ng, A. Andriyana, E. Verron, O. Kahbasi, R. Ahmad, Development of a Novel Experimental Device to Investigate Swelling of Elastomers in Biodiesel Undergoing Multiaxial Large Deformation, Experimental Mechanics, (2013) 1-10.

[17] S. Ch'ng, A. Andriyana, E. Verron, O. Kahbasi, R. Ahmad, Development of a Novel Experimental Device to Investigate Swelling of Elastomers in Biodiesel Undergoing Multiaxial Large Deformation, Experimental Mechanics, (2013) 1-10.

[18] A.B. Chai, A. Andriyana, E. Verron, M.R. Johan, Mechanical characteristics of swollen elastomers under cyclic loading, Materials \& Design, 44 (2013) 566-572. 
[19] M.A. Kader, A.K. Bhowmick, Thermal ageing, degradation and swelling of acrylate rubber, fluororubber and their blends containing polyfunctional acrylates, Polym. Degrad. Stab., 79 (2003) 283-295.

[20] G. Nasr, A. Gomaa, The influence of physical ageing on the electrical and swelling behaviour of ternary rubber vulcanizates, Polym. Degrad. Stab., 50 (1995) 249-259.

[21] J. Beatty, Fatigue of rubber, Rubber Chem. Technol., 37 (1964) 1341-1364.

[22] S. Svensson, Testing methods for fatigue properties of rubber materials and vibration isolators, Polymer Testing, 2 (1981) 161-174.

[23] N. André, G. Cailletaud, R. Piques, Haigh diagram for fatigue crack initiation prediction of natural rubber components, Kautsch. Gummi Kunstst., 52 (1999) 120-123.

[24] K. Legorju-Jago, C. Bathias, Fatigue initiation and propagation in natural and synthetic rubbers, International Journal of Fatigue, 24 (2002) 85-92.

[25] N. Saintier, G. Cailletaud, R. Piques, Crack initiation and propagation under multiaxial fatigue in a natural rubber, International Journal of Fatigue, 28 (2006) 61-72.

[26] M.S. Loo, J.-B. Le Cam, A. Andriyana, E. Robin, Afifi.A, Fatigue of swollen elastomers, International Journal of Fatigue, 74 (2015) 132-141.

[27] F. Horkay, D.C. Lin, Mapping the Local Osmotic Modulus of Polymer Gelst, Langmuir, 25 (2009) 8735-8741.

[28] J. Benkahla, T. Baranger, J. Issartel, Fatigue Life Estimation for an NBR Rubber and an Expanded Polyurethane, Experimental Mechanics, 53 (2013) 1383-1393.

[29] A. Andriyana, N. Saintier, E. Verron, Configurational Mechanics and Critical Plane Approach: Concept and application to fatigue failure analysis of rubberlike materials, International journal of fatigue, 32 (2010) 1627-1638.

[30] B. Roberts, J. Benzies, The relationship between uniaxial and equibiaxial fatigue in gum and carbon black filled vulcanizates, Proceedings of rubbercon, 77 (1977) 2.1-2.13.

[31] C. Lu, Etude du comportement mécanique et des mécanismes d'endommagement des élastomères en fatigue et en fissuration par fatigue, PhD Thesis, Conservatoire National des Arts et Métiers, (1991).

[32] J. Xie, Etude de la fatigue et de la rupture des assemblages collés composite-élastomère, PhD Thesis, Ecole Centrale de Paris, (1992).

[33] W. Mars, A. Fatemi, Multiaxial fatigue of rubber: Part I: equivalence criteria and theoretical aspects, Fatigue \& fracture of engineering materials \& structures, 28 (2005) 515-522.

[34] E. Richaud, F. Djouani, B. Fayolle, J. Verdi, B. Flaconneche, New Insights in Polymer-Biofuels Interaction, Oil \& Gas Science and Technology-Revue d'IFP Energies nouvelles, (2013).

[35] L.R.G. Treloar, The Physics of Rubber Elasticity, Oxford University Press, 1975.

[36] J.-B. Le Cam, B. Huneau, E. Verron, Failure analysis of carbon black filled styrene butadiene rubber under fatigue loading conditions, Plastics, Rubber and Composites, 43 (2014) 187-191. 